\title{
BMJ Open Understanding the motivation and performance of community health volunteers involved in the delivery of health programmes in Kampala, Uganda: a realist evaluation
}

\author{
Gaëlle Vareilles, ${ }^{1,2}$ Bruno Marchal, ${ }^{3}$ Sumit Kane, ${ }^{4}$ Taja Petrič, ${ }^{5}$ Gabriel Pictet, ${ }^{5}$ \\ Jeanine Pommier ${ }^{1,2}$
}

To cite: Vareilles $\mathrm{G}$, Marchal B, Kane S, et al. Understanding the motivation and performance of community health volunteers involved in the delivery of health programmes in Kampala, Uganda: a realist evaluation. BMJ Open 2015;5:e008614. doi:10.1136/bmjopen-2015008614

- Prepublication history and additional material is available. To view please visit the journal (http://dx.doi.org/ 10.1136/bmjopen-2015008614).

Received 28 April 2015 Revised 26 August 2015 Accepted 2 September 2015

CrossMark

For numbered affiliations see end of article.

Correspondence to Dr Gaëlle Vareilles; Vareilles.gaelle@gmail.com

\section{ABSTRACT}

Objectives: This paper presents the results of a realist evaluation that aimed to understand how, why and under what circumstances a Red Cross (RC) capacitybuilding intervention influences the motivation and the performance of $\mathrm{RC}$ community health volunteers involved in the delivery of an immunisation programme in Kampala, Uganda.

Method: Given the complexity of the intervention, we adopted realist evaluation as our methodological approach and the case study as our study design. Data collection included document review, participant observation and interviews. The constant comparative method was used for the analysis. Two contrasted cases were selected within the five Kampala districts. Each case covers the management of the immunisation programme implemented at a RC branch. In each case, a programme manager and $15 \mathrm{RC}$ volunteers were interviewed. The selection of the volunteers was purposive.

Results: We found that a capacity-building programme including supervision supportive of autonomy, skills and knowledge enhancement, and adapted to the different subgroups of volunteers, leads to satisfaction of the three key drivers of volunteer motivation: feelings of autonomy, competence and connectedness. This contributes to higher retention, and better task performance and wellbeing among the volunteers. Enabling contextual conditions include the responsiveness of the Uganda Red Cross Society (URCS) to community needs, and recognition of the work of the volunteers, from the URCS and the community.

Conclusions: A management approach that caters for the different motivational states and changing needs of the volunteers will lead to better performance. The findings will inform not only the management of community health volunteers, but also the management of all kinds of health workers.

\section{INTRODUCTION}

The 2012 Mexico City Political Declaration on Universal Health coverage recognised the
Strengths and limitations of this study

- To the best of our knowledge, this is the first published realist inquiry of motivation and management of community health volunteers.

- The realist approach allowed identification of mechanisms and conditions through which capacity-building programmes improve the performance of volunteers.

- Limitations include the lack of data on the profiles of volunteers and an inability to fully assess outcomes such as task performance and retention.

'efforts of government and civil society ... to make progress within their health systems towards universal health coverage'. ${ }^{1}$ Areas of ongoing collaboration include disease prevention, health promotion, and enhancement of the capacity of health systems as well as healthcare workers.

Experience has shown that community health volunteers-lay persons who provide health services within a formal structure on a voluntary basis-represent an important resource. Trained and supported volunteers, such as the millions working with non-profit organisations or in corporate community programmes, can deliver crucial and culturally sensitive health messages, and empower individuals, households and communities to make informed decisions and increase local access to lifesaving curative measures. ${ }^{2-7}$ The effectiveness of community health volunteers to improve community health outcomes is, however, being questioned. ${ }^{8-11}$ Low performance associated with a high attrition rate has been reported in many programmes. ${ }^{12-14}$

The success of community health interventions is likely to depend on the implementation of the local capacity-building strategy 
and on local conditions, such as in the organisational context. $^{2} 46 \quad 12$ 15-17 Programme managers can play a major role in motivating volunteers through their managerial practices (how they administer the organisation, execute plans and policies, and pursue objectives) ${ }^{18}$ and leadership style (the capacity to translate a vision into a source of inspiration that mobilises volunteers). ${ }^{18}$ Indeed, programme managers are directly involved in activities designed to attract, orientate, retain and manage volunteers. Moreover, research in the field of organisational psychology has shown that leadership supportive of autonomy, characterised as understanding and acknowledging subordinates' perspectives, giving opportunities for choice, supporting competences and encouraging personal initiative, ${ }^{19}{ }^{20}$ can motivate a volunteer to stay engaged and to perform well. ${ }^{21}$

However, despite the recent research on volunteer motivation and performance, what motivates community health volunteers is still debated. ${ }^{22}$ Further research is needed regarding the influence of managerial practices and leadership styles on volunteers' intentions to become and remain volunteers, on their perception of job satisfaction and on why they may not remain engaged. $^{21} 2324$

Some reasons for this knowledge gap are the methodological difficulties in embracing the complexity of human behaviour in organisations. Red Cross Red Crescent (RCRC) National Societies implement capacitybuilding programmes based on training, supervision and support, in order to develop a pool of capable volunteers who can improve the health of underserved communities. These interventions involve action at three levels: (1) improving knowledge and skills, (2) supporting infrastructure and (3) developing partnerships. ${ }^{25}$ Such community health volunteer interventions are thus complex interventions. They are embedded within multifaceted health and social systems, and the success of such intervention is highly context-dependent. This not only raises questions about the applicability of results of one study to different settings, but it also requires using appropriate study designs and methodologies. $^{26-28}$

The International Federation of Red Cross and Red Crescent Societies (IFRC) is in the process of reviewing its strategies for addressing health issues (eg, infectious disease prevention, ageing, prevention of noncommunicable diseases, home management of chronic conditions, mental health) through volunteer-based community approaches. These strategies will be informed by a multicase study programme of RCRC Community-Based Health $(\mathrm{CBH})$ projects worldwide. The first in the series is a case study in Uganda, where the Ugandan Red Cross Society (URCS) requested an assessment of their CBH immunisation project. The purpose of the assessment was to address the evidence gap on volunteer management by focusing on volunteer motivation, its underlying processes and the influence of context.
This article presents the results of the study in Uganda, which aimed to understand how, why and under what circumstances the URCS capacity-building intervention shapes the motivation of volunteers and contributes to better performance.

The specific objectives were to:

- Describe the managerial practices and leadership styles at a RC branch level, framed against the organisational context.

- Analyse how the managerial practices and leadership styles and the organisational context influence the work attitudes and work behaviour of the volunteers.

- Identify the plausible mechanisms of change that explain the above linkage (or lack of it).

\section{BACKGROUND}

\section{The setting}

Uganda remains one of the world's most impoverished countries, and healthcare performance is still ranked as one of the worst in the world ${ }^{29}$ despite recent rapid economic growth. Uganda is also one of Africa's most rapidly urbanising countries, ${ }^{30}$ and almost $50 \%$ of the population is below 15 years of age. ${ }^{31}$ The high rate of urban growth in the capital, Kampala, contributes to unhealthy environments with inadequate infrastructure and weak social services. Kampala has the highest proportion of unimmunised children in Uganda. The URCS, in its auxiliary role to the government, contributes to strengthening routine immunisation in nine selected underperforming districts, including five in Kampala.

The URCS is a prestigious and leading humanitarian organisation in Uganda. Its mission includes saving lives, supporting livelihoods and promoting human dignity. ${ }^{32}$ It has a country-wide structure in place (headquarters in Kampala, offices in 5 regions, and 51 branches). The URCS branches constitute management and governance structures, usually created to operate around established government district structures. In each district, one RC branch manager and a team of volunteers coordinate, monitor and document all programme activities.

Community members are generally willing to support the organisation. The community demand for URCS's services is an opportunity to join and volunteer. While volunteers' profiles vary, those in Kampala are mostly young, well-educated and unemployed. These young volunteers have high expectations and typically volunteer for short periods. As a consequence, the URCS experiences difficulties in retaining them. A figure providing an overview of the URCS structure, mission and profile of volunteers is available in online supplementary annexe 1.

\section{The URCS capacity-building intervention for the} immunisation programme

The RC immunisation programme consists of providing communication and social mobilisation support and has 
been implemented three times, between June 2013 and January 2014. The main role of RC volunteers is to conduct house-to-house sensitisation, organise orientation meetings with community members, and provide a link between the health facilities and the community.

The volunteers receive 1 day's training from the URCS and 3 day's training from the Ministry of Health and UNICEF to implement the immunisation programme. The training provides relevant technical information on immunisation, strengthens skills and introduces tools to mobilise the community and address negative attitudes towards immunisation services. Tools such as posters and field guides are provided, and a small allowance (7500 Uganda shillings per day) is given to compensate for the costs related to involvement. Technical support and guidance are provided to the programme managers and volunteers by MoH-UNICEF on data collection, analysis and reporting.

In each Kampala district, a programme manager is responsible for implementing, coordinating and supervising the activities of the volunteers involved in the immunisation programme. The community volunteers are recruited from the RC pool of active volunteers by the programme manager and by public announcements (482 volunteers deployed in Kampala West and 1060 in Kampala East during the second round of the immunisation campaign). 'Active' in this case is defined as a volunteer who has repeatedly shown interest in taking part in different RC activities or who has had previous experience in community health. A contract is signed and the individual volunteer's skills and expectations are noted. The programme manager sets goals for volunteers and assigns their tasks. Some volunteers are recruited as team leaders and their role is to mobilise the community volunteers. As part of the daily work, the programme manager organises meetings with the volunteers at the branch office, provides feedback on the work performed, and allocates supplies and equipment.

\section{METHODS}

The overall methodological approach: a realist evaluation

Because the RC CBH capacity-building intervention has all the features of a complex intervention, we used the realist evaluation approach. (See the protocol of the evaluation for a detailed discussion of the methodological approach and its justification). ${ }^{33}$

Realist evaluation belongs to the school of theorydriven inquiry and seeks to answer why, how and under what circumstances an intervention would deliver (or not deliver) the desired outcomes. ${ }^{34}$ It starts and ends with a theory. The evaluator begins with the formulation of the initial programme theory (PT), that is, the designers' and other stakeholders' assumptions around which the programme was planned, and which explains why the programme should reach its objectives. The initial PT represents an explicit hypothesis that can be tested and further developed through empirical research. The end result of a realist evaluation is a refined set of assumptions, namely, a refined PT, which provides information on what kind of interventions worked for whom, under which conditions and how. ${ }^{35}$ If insights accumulate as a result of a series of realist evaluation studies, the results can attain the level of middle range theory. These are theories in between grand universal theories and the more specific PT.

We documented the development of the initial PT underlying capacity-building strategies for volunteers in the protocol. ${ }^{33}$ The initial PT emerged from interviews with key stakeholders and literature reviews, including a realist review on community health volunteer performance and a review of existing theories in the field of management and organisational behaviour. Self-determination theory (SDT) serves as the basis of the PT. SDT represents a broad framework for the study of human motivation, and allows for the assessment of both level and quality of motivation. ${ }^{36}$ The main concepts of the SDT framework are described in online supplementary annexe 2 .

The initial PT-which explains the link between an intervention, the context, the underlying mechanisms of change (psychosocial or social explanations for volunteers' choice and behaviour) and the expected outcomes (figure 1)—stated that:

\begin{abstract}
Management practices and leadership styles (intervention) that are supportive of autonomy lead to positive work behaviour of volunteers, such as improved task performance and persistence (outcomes), because they satisfy the psychological needs of autonomy, competence and relatedness (mechanism). More specifically, such management and leadership contribute to a shift from 'external motivation' towards 'internalised motivation' for the volunteers whose initial engagement was more driven by external motives. Internalised motivation leads not only to positive work behaviour, but also to wellbeing. Such management and leadership furthermore allow volunteers whose initial engagement was mainly driven by internal motives to remain engaged and perform well.
\end{abstract}

Other conditions for such outcomes to be attained include the organisational context, whereby a good match of the organisational culture and mission with the volunteers' expectations matters, and resource availability (context).

\section{A case study design}

In realist evaluation, the choice of the design is informed by the PT. We chose the case study design in order to 'test' the different elements of the PT. Case studies are useful to explore how and why social phenomena work. This design allows for an in-depth exploration of the interrelationship of context, intervention, mechanisms and outcomes as they occur in their natural setting. ${ }^{37}$ In realist evaluation, cases are often selected purposively, and often include contrasting cases, because 


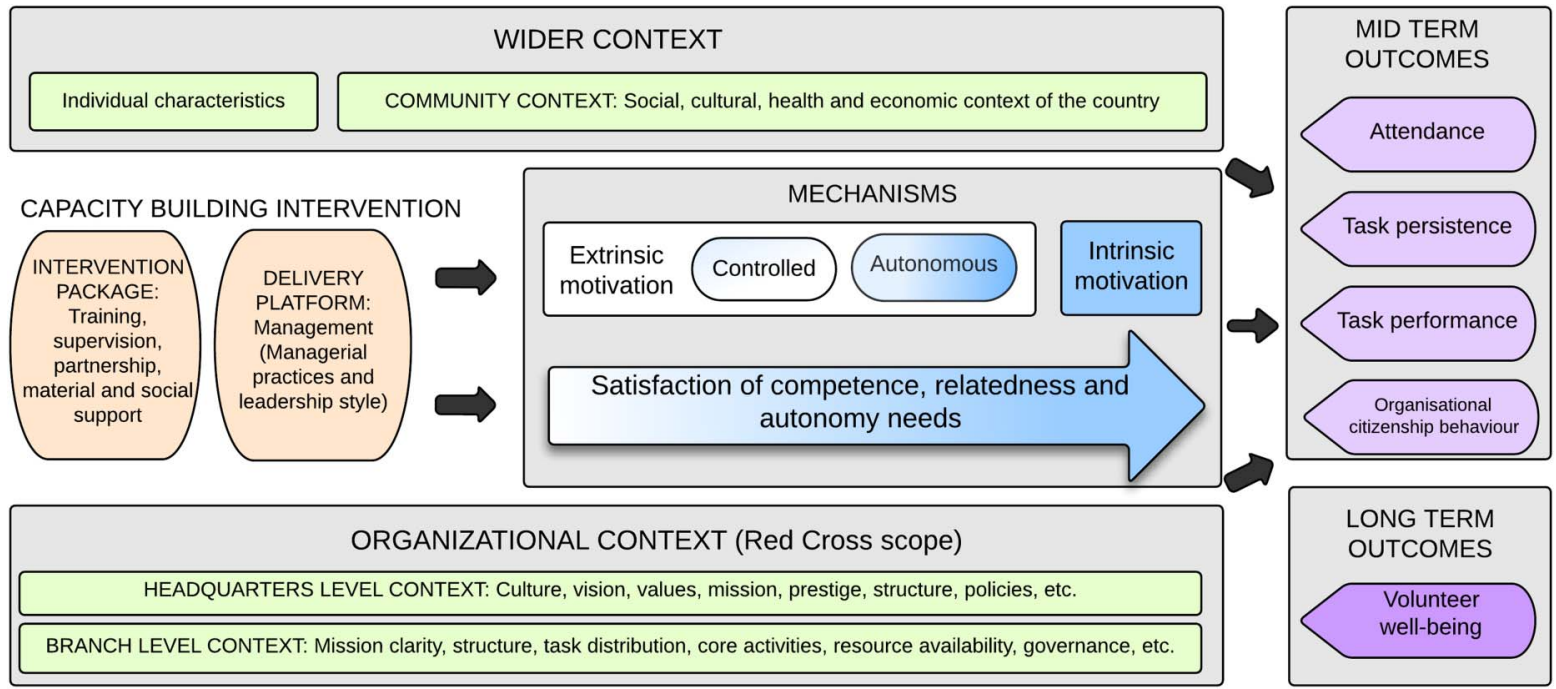

Figure 1 The initial programme theory underlying volunteers' capacity-building strategies (adapted from the study protocol ${ }^{33}$ ).

these offer better conditions to see which elements of the PT either hold or do not hold.

We defined a case as a RC branch unit operating in one district. In conjunction with URCS, we chose the East and West branches because they presented variation in terms of leadership and managerial practices, resources and turnover of volunteers.

\section{Data collection}

Realist evaluation is method neutral; the choice of the data collection is determined by the nature of the research question and the initial $\mathrm{PT}^{34}$ Two of the authors visited Kampala East and West, and collected data through document review, individual interviews, focus group discussions (FDGs) and observation. The data collection took place between March 2014 and December 2014.

First, information on the overall RC organisational context was collected through a review of URCS documents and discussion with the URCS staff. Second, information was collected locally at each case site. We conducted interviews with volunteers and programme managers to describe the RC management and the organisational context, and to understand how these shape the motivation and performance of volunteers. Observation and discussion with the main stakeholders involved in the immunisation campaign and with community members allowed us to describe the implementation context at branch level, the broader context surrounding the URCS volunteers and the behaviour of volunteers.

\section{Individual interviews and FDGs}

We conducted in-depth individual interviews with 19 volunteers and held one FDG per branch. In total, we had 30 interviewees and focus group participants. We conducted FDGs with volunteers, to investigate issues that would remain hidden when conducting individual interviews, as FDGs provide for a reflective environment where participants can share varied views on the subject under investigation. ${ }^{38}$

To enable exploration of the influence of context, leadership and management practices on a variety of individual volunteers, the selection of volunteers was purposive. Regarding individual in-depth interviews, volunteers with different profiles were interviewed. These profiles included one chairperson of the branch governing board, 5 branch volunteers and 13 community volunteers. Some of the volunteers interviewed were volunteering every day, others volunteered only when asked to or when they were a part of a project, such as the immunisation campaign. Table 1 shows the main characteristics of the individual respondents and their distribution in the two branches.

We used a semistructured interview guide with open questions, which included questions to identify the characteristics and the motives of the volunteers who join the RC, the capacity-building intervention and its observed outcomes. Questions included:

- What motivated the volunteers to join the RC?

- What are the capacity-building strategies implemented by the RG?

- What are the observed outcomes of the capacitybuilding strategies implemented by the RC?

The guide also included questions exploring the contribution of the RC management strategies to the observed outcome:

- How can the link between the intervention and results be explained? What mechanisms drove the actors to make decisions in the light of the programme?

- Which context conditions facilitated these decisions? Which conditions are essential?

- Are there alternative explanations (ie, other interventions that took place)? 
Table 1 Characteristics of volunteers for in depth individual interviews

\begin{tabular}{|c|c|c|}
\hline $\begin{array}{l}\text { Respondents } \\
\text { (active volunteers) }\end{array}$ & $\begin{array}{l}\text { Number of } \\
\text { interviews in } \\
\text { Kampala West }\end{array}$ & $\begin{array}{l}\text { Number of } \\
\text { interviews in } \\
\text { Kampala East }\end{array}$ \\
\hline Total number & 9 & 10 \\
\hline \multicolumn{3}{|l|}{ Age } \\
\hline $20-25$ years old & 5 & 2 \\
\hline $26-30$ years old & 2 & 3 \\
\hline $31-35$ years old & 1 & 1 \\
\hline $\begin{array}{l}36 \text { years old or } \\
\text { more }\end{array}$ & 1 & 4 \\
\hline \multicolumn{3}{|l|}{ Gender } \\
\hline Male & 7 & 3 \\
\hline Female & 2 & 7 \\
\hline \multicolumn{3}{|l|}{$\begin{array}{l}\text { Year(s) volunteering } \\
\text { with } R C\end{array}$} \\
\hline $1-3$ & 4 & 3 \\
\hline $4-10$ & 3 & 4 \\
\hline More than 10 & 2 & 3 \\
\hline \multicolumn{3}{|l|}{ Employment } \\
\hline Unemployed & 1 & 3 \\
\hline $\begin{array}{l}\text { Self-employed or } \\
\text { working on grey } \\
\text { market }\end{array}$ & 3 & 3 \\
\hline Employed & 5 & 3 \\
\hline Unknown & 0 & 1 \\
\hline Students & 2 & 2 \\
\hline
\end{tabular}

\section{Observation and discussions}

In each case, we observed the volunteers and the programme managers during a whole week. Observation and discussions, documented through note-taking, were conducted at the branch office during field visits in the community and at health facilities. Additionally, to more specifically describe the level of autonomy support provided by the programme manager, we used a questionnaire to guide the discussion with the programme managers. This questionnaire was adapted from the Problems at Work Questionnaire of Deci et $a l^{39}$ and assesses whether individuals in a position of authority tend to be oriented towards controlling the behaviour or supporting their autonomy.

Table 2 summarises the data collection techniques and table 3 provides details on the data collection process.

\section{Data analysis}

During the data analysis, the initial PT guided the identification of emerging themes. We used the constant comparative analysis technique. ${ }^{40}$ Data were classified and organised according to key themes, concepts and emergent patterns. Furthermore, drawing on Ragin's recommendations on comparative case study research, ${ }^{41}$ each case was first examined as a whole and the two cases were then compared with each other.
The analysis was conducted as follows. First, a search for potential patterns was carried out. We searched for the link between observed outcomes and the intervention through mechanisms that were triggered for specific actors in specific contexts. ${ }^{34}$ This step included five main activities:

- The interviews were transcribed verbatim and the first author in collaboration with the co-authors read through the transcripts to identify patterns relevant to the main research questions.

- A predefined coding system based on the initial PT (volunteer characteristics, managerial practices and leadership styles, extrinsic and intrinsic motivation, satisfaction of psychological needs, organisational culture, value and mission, etc) was used. The coding tree evolved as relevant issues emerged from the analysis, for instance, the variation of drivers of motivation in function of time spent with the RC.

- Next, data were coded to themes, and a table was developed to compare both cases. The themes from each data set were arranged according to their reference to context, interventions, outcomes and mechanisms.

- Using the tables, we identified conjectural Context Mechanism Outcome (CMO) configurations that explained the observed outcomes of retention, productivity and well-being. Triangulation of findings was carried out: we combined data from different sources (observation notes, focus groups, secondary document analysis).

- We then assessed whether the conjectural configurations provided plausible explanations in the other case. This cross case comparison helped in assessing whether and how the same mechanisms play out in different contexts to produce different outcomes.

\section{Ethical considerations}

Ethical approval for this inquiry was granted by the Ethical Committee of the University Hospital in Rennes, France (CHU Rennes Hotel Dieu-Rennes, FranceApproval number 14.41).

The selected volunteers had the option to decline participating in the study. They were informed that nonparticipation in the study would not affect their further work for the URCS. Written consent was sought from each respondent before the interviews. Approval for audio recording of interviews was sought separately. A code was given to questionnaire and interview transcripts to ensure confidentiality of all opinions expressed by participants. The preliminary results were presented to the participants for validation, and their suggestions and comments have been included in the findings.

\section{RESULTS}

We present the results in three parts: the intervention and context, the mechanisms and the Context Mechanisms Outcome configurations. 
Table 2 Overview of data sources

\begin{tabular}{|c|c|c|c|c|c|c|c|}
\hline \multirow[b]{2}{*}{ PT element } & \multirow[b]{2}{*}{ Dimension } & \multicolumn{2}{|c|}{ Individual interview } & \multirow{2}{*}{$\begin{array}{l}\text { Focus } \\
\text { group } \\
\text { with } \\
\text { volunteers }\end{array}$} & \multirow{2}{*}{$\begin{array}{l}\text { Discussion } \\
\text { with key } \\
\text { informants }\end{array}$} & \multirow[b]{2}{*}{ Observation } & \multirow[b]{2}{*}{$\begin{array}{l}\text { Document } \\
\text { review }\end{array}$} \\
\hline & & Volunteers & $\begin{array}{l}\text { Programme } \\
\text { managers }\end{array}$ & & & & \\
\hline Outcomes & $\begin{array}{l}\text { Volunteer retention } \\
\text { Task performance } \\
\text { Organisational } \\
\text { citizenship } \\
\text { Behaviour } \\
\text { Well-being }\end{array}$ & $x$ & $x$ & $x$ & $x$ & & $x$ \\
\hline $\begin{array}{l}\text { Intermediary } \\
\text { outcomes }\end{array}$ & $\begin{array}{l}\text { Motivation } \\
\text { Intention to quit } \\
\text { Absenteeism }\end{array}$ & $x$ & $x$ & $x$ & $x$ & & $x$ \\
\hline Intervention & $\begin{array}{l}\text { Management activities } \\
\text { and practices }\end{array}$ & $x$ & $x$ & $x$ & $x$ & $x$ & $x$ \\
\hline Mechanisms & $\begin{array}{l}\text { Competence } \\
\text { Autonomy } \\
\text { Relatedness } \\
\text { Mission valence }\end{array}$ & $x$ & & $x$ & & & \\
\hline \multirow[t]{3}{*}{ Context } & $\begin{array}{l}\text { Organisational context } \\
\text { at branch level }\end{array}$ & $x$ & $x$ & $x$ & & $x$ & $x$ \\
\hline & $\begin{array}{l}\text { Organisational context } \\
\text { at national level (URCS) }\end{array}$ & & & & $x$ & $x$ & $x$ \\
\hline & Country context & & & & $x$ & $x$ & $\mathrm{x}$ \\
\hline
\end{tabular}

\section{Intervention and context}

We observed similarities regarding the intervention and its context of implementation. In general, both branch managers involved the volunteers in first aid and community services, assessments during emergencies, youth camps, membership recruitment networking and collaborative ventures, dissemination of RC information, meetings, social mobilisation and sporting activities, and income-generating activities. However, we noted more opportunities for volunteers to be involved in wellstructured activities or projects in Kampala East with several health prevention activities and more development of income-generating activities. Both programme managers were in close relationship with the volunteers working at the branch office, and organised to meet the volunteers working in the community. They were always reachable and volunteers could call them for support if they experienced difficulties. They organised weekly meetings for the office volunteers and a platform group discussion, and provided skill-building and problem-solving support (regarding conflict resolution, and including key messages to provide, reporting and writing). The delegation of responsibilities to the office volunteers was made explicit. Finally, they provided feedback to all volunteers on the work performed based on discussion with partners and the community.

There were also differences in the implementation of the capacity-building intervention. Volunteers in the East branch benefited from additional skill-based training in leadership and community-based healthcare.
Also, the background of the programme manager and the strong HIV programme in the recent past in the East branch contributed to a higher capacity to train volunteers in health-related activities. Further opportunities for training outside the RC were also provided, due to strong collaboration with local partners.

Regarding leadership practices, both programme managers provided opportunities for autonomy. However, some differences regarding their leadership styles emerged from our observation and interviews. Using the typology of Pearce et $a l,{ }^{42}$ we noticed, in the Kampala West branch, components of transformational leadership (eg, being accessible, enabling, inspiring others, being decisive), whereas in the East branch, we observed components of empowerment leadership (such as opportunity thinking, enhancing team work, opportunity for self-development, participating in goal-setting).

Table 4, below, summarises the main differences between Kampala East and West, in terms of implementation of the local intervention and organisational context.

\section{The mechanisms}

We found that in both branches, the RC management and the community response had an impact on the key drivers of volunteer motivation (satisfaction of competence, autonomy and relatedness needs). The satisfaction of these three basic psychological needs was described by the volunteers as feelings of self-efficacy and having the ability to organise their work, feelings of 
Table 3 Details of data collection process

\begin{tabular}{|c|c|c|c|c|c|}
\hline Method & Key informants & $\begin{array}{l}\text { Number of key } \\
\text { informants }\end{array}$ & Length and place & Tools & Purpose \\
\hline \multirow[t]{2}{*}{$\begin{array}{l}\text { Individual } \\
\text { interview }\end{array}$} & URCS volunteers & $\begin{array}{l}19 \text { (10 East branch, } 9 \\
\text { West branch) }\end{array}$ & $\begin{array}{l}\text { 45-60 min } \\
\text { Various } \\
\text { locations (home, } \\
\text { work place, } \\
\text { branch office) }\end{array}$ & $\begin{array}{l}\text { Semistructured interview } \\
\text { guide } \\
\text { Both interviewers } \\
\text { present in } 14 \text { interviews } \\
\text { Recorded } \\
\text { Translator used for } 8 \\
\text { interviews }\end{array}$ & $\begin{array}{l}\text { To understand the management } \\
\text { and context shaping the motivation } \\
\text { and organisational behaviour of } \\
\text { volunteers }\end{array}$ \\
\hline & Programme manager & $\begin{array}{l}2 \text { (1 East branch, } 1 \\
\text { West branch) }\end{array}$ & $\begin{array}{l}\text { 60-90 min per } \\
\text { interview } \\
\text { Branch office }\end{array}$ & $\begin{array}{l}\text { Semistructured interview } \\
\text { guide } \\
\text { Both interviewers } \\
\text { present } \\
\text { - Recorded }\end{array}$ & $\begin{array}{l}\text { To understand the management } \\
\text { and context shaping the motivation } \\
\text { and organisational behaviour of } \\
\text { volunteers }\end{array}$ \\
\hline $\begin{array}{l}\text { Focus } \\
\text { groups }\end{array}$ & $\begin{array}{l}\text { URCS volunteers involved in the } \\
\text { immunisation campaign }\end{array}$ & $\begin{array}{l}2 \text { groups ( } 1 \text { group of } 9 \\
\text { volunteers in East } \\
\text { branch, } 1 \text { group of } 9 \\
\text { volunteers in West } \\
\text { branch) }\end{array}$ & $\begin{array}{l}2 \mathrm{~h} \text { per focus } \\
\text { group } \\
\text { Branch office or } \\
\text { community }\end{array}$ & $\begin{array}{l}\text { Semistructured interview } \\
\text { guide } \\
\text { Both interviewers } \\
\text { present in } 3 \text { discussions } \\
\text { Translator used for } 1 \\
\text { group } \\
\text { Notes taken }\end{array}$ & $\begin{array}{l}\text { To understand the management } \\
\text { and context shaping the motivation } \\
\text { and organisational behaviour of } \\
\text { volunteers }\end{array}$ \\
\hline \multirow[t]{2}{*}{ Observation } & Programme manager & $\begin{array}{l}2 \text { ( } 1 \text { East branch, } 1 \\
\text { West branch) }\end{array}$ & $\begin{array}{l}1 \text { week } \\
\text { Branch office } \\
\text { and field }\end{array}$ & $\begin{array}{l}\text { Both interviewers } \\
\text { present } \\
\text { - Field notes taken }\end{array}$ & $\begin{array}{l}\text { To describe the leadership styles } \\
\text { and managerial practices of } \\
\text { programme managers }\end{array}$ \\
\hline & $\begin{array}{l}\text { URCS volunteers involved in the } \\
\text { immunisation campaign }\end{array}$ & $\begin{array}{l}20 \text { (10 East Branch, } 10 \\
\text { West Branch) }\end{array}$ & $\begin{array}{l}1 \text { week. } \\
\text { Branch office } \\
\text { and field }\end{array}$ & $\begin{array}{l}\text { Both interviewers } \\
\text { present } \\
\text { Field notes taken }\end{array}$ & $\begin{array}{l}\text { To describe the context at branch } \\
\text { level: that is, the branch team } \\
\text { Group dynamics, manager/ } \\
\text { volunteer interaction, to describe } \\
\text { the outcomes: volunteer } \\
\text { behaviours }\end{array}$ \\
\hline \multirow[t]{2}{*}{ Discussion } & Programme manager & $\begin{array}{l}2 \text { (1 East Branch, } 1 \\
\text { West Branch) }\end{array}$ & $1 \mathrm{~h}$ discussion & $\begin{array}{l}\text { Questionnaire adapted from } \\
\text { the Problems at Work } \\
\text { Questionnaire of Deci } \\
\text { et } a \beta^{\beta 9 ~} 40\end{array}$ & $\begin{array}{l}\text { To describe the level of autonomy } \\
\text { support provided by the } \\
\text { programme manager }\end{array}$ \\
\hline & $\begin{array}{l}\text { URCS staff (CBHFA programme } \\
\text { manager, director youth and } \\
\text { organisational development, director }\end{array}$ & 4 & $\begin{array}{l}1 \mathrm{~h} \text { discussion } \\
\text { RC } \\
\text { headquarters in } \\
\text { Kampala }\end{array}$ & $\begin{array}{l}\text { Questionnaire } \\
\text { Using a typology of } \\
\text { context tool }\end{array}$ & $\begin{array}{l}\text { To describe the overall } \mathrm{RC} \\
\text { organisational context: structure, } \\
\text { mission, culture, policies, core }\end{array}$ \\
\hline
\end{tabular}




\begin{tabular}{|c|c|c|c|c|c|}
\hline Method & Key informants & $\begin{array}{l}\text { Number of key } \\
\text { informants }\end{array}$ & Length and place & Tools & Purpose \\
\hline & \multicolumn{2}{|l|}{$\begin{array}{l}\text { youth and volunteer management, } \\
\text { community health coordinator) }\end{array}$} & & \multirow{2}{*}{$\begin{array}{l}\text { Both interviewers } \\
\text { present } \\
\text { Field notes taken } \\
\text { Informal visit } \\
\text { Both interviewers } \\
\text { present } \\
\text { - Field notes taken }\end{array}$} & $\begin{array}{l}\text { activities, resources, organisational } \\
\text { development of volunteers... }\end{array}$ \\
\hline & $\begin{array}{l}\text { Government or private health } \\
\text { facilities 'staff' }\end{array}$ & 8 & $\begin{array}{l}1-3 \mathrm{~h} \\
\text { discussions per } \\
\text { location } \\
\text { Private and } \\
\text { government } \\
\text { health facility } \\
\text { (West branch) } \\
\text { Public health } \\
\text { department } \\
\text { (East branch) }\end{array}$ & & $\begin{array}{l}\text { To describe the government/private } \\
\text { sector health context and } \\
\text { professionals' attitudes towards the } \\
\text { RC volunteers }\end{array}$ \\
\hline & $\begin{array}{l}\text { Community members: local leaders, } \\
\text { professors, students, beneficiaries }\end{array}$ & 20 & $\begin{array}{l}1-3 \mathrm{~h} \\
\text { discussions per } \\
\text { location } \\
\text { Various } \\
\text { locations } \\
\text { (Schools, } \\
\text { university, } \\
\text { workplace, } \\
\text { home...) }\end{array}$ & $\begin{array}{l}\text { Informal visit } \\
\text { Both interviewers } \\
\text { present } \\
\text { Field notes taken }\end{array}$ & $\begin{array}{l}\text { To describe the community context } \\
\text { and community members' attitudes } \\
\text { towards the RC volunteers }\end{array}$ \\
\hline
\end{tabular}


Table 4 Implementation of the intervention and organisational context: main differences in the two cases

\begin{tabular}{|c|c|c|}
\hline Dimension & Kampala West & Kampala East \\
\hline \multicolumn{3}{|c|}{ Implementation of the intervention } \\
\hline \multirow{3}{*}{$\begin{array}{l}\text { Training and refresher } \\
\text { course }\end{array}$} & $\mathrm{RC}$ principles and mission & \\
\hline & First aid training & CBHFA training \\
\hline & & Leadership skills \\
\hline \multirow{3}{*}{$\begin{array}{l}\text { Management practices and } \\
\text { leadership style }\end{array}$} & Transformational leadership & Empowerment leadership \\
\hline & & Role-playing activities \\
\hline & & Encourage a learner-centred process \\
\hline \multirow[t]{2}{*}{ Partnership } & With local partners & \\
\hline & & $\begin{array}{l}\text { Joint training for volunteers with local } \\
\text { authority }\end{array}$ \\
\hline \multicolumn{3}{|l|}{ Organisational context } \\
\hline \multirow[t]{4}{*}{ Characteristics of PM } & Male & Male \\
\hline & 29 years old & 44 years old \\
\hline & PM since 2013 & PM since 2009 \\
\hline & $\begin{array}{l}\text { Experience as RC instructor National disaster } \\
\text { responders team for URCS }\end{array}$ & Experience in management and healthcare \\
\hline \multirow[t]{8}{*}{ Core activities } & Dissemination & \\
\hline & First aid and road safety & \\
\hline & Emergency response to disaster & \\
\hline & Adolescent reproductive and sexual health & \\
\hline & Community services & \\
\hline & Blood donor recruitment & \\
\hline & Resource mobilisation team & \\
\hline & & $\begin{array}{l}\text { HIV prevention activitiesActivities related to } \\
\text { IGA }\end{array}$ \\
\hline \multirow[t]{3}{*}{ Knowledge of RC mission } & Knowledge of RC principles and mission & \\
\hline & $\begin{array}{l}\text { Few of the board members had seen and } \\
\text { read the URCS strategic plan }\end{array}$ & $\begin{array}{l}\text { Board members aware of the URCS strategic } \\
\text { plan }\end{array}$ \\
\hline & & Well-articulated branch development plan \\
\hline \multirow[t]{2}{*}{$\begin{array}{l}\text { Governance and policy } \\
\text { implementation }\end{array}$} & $\begin{array}{l}\text { Hold the four mandatory statutory board } \\
\text { meetings with full board participation }\end{array}$ & $\begin{array}{l}\text { Hold all statutory board meetings with full } \\
\text { board participation }\end{array}$ \\
\hline & & Implementation of board recommendations \\
\hline $\begin{array}{l}\text { Human resource } \\
\text { management }\end{array}$ & $\begin{array}{l}\text { Recent improvement in volunteer } \\
\text { management system }\end{array}$ & $\begin{array}{l}\text { Volunteer management systems in form of } \\
\text { records of volunteers kept in file }\end{array}$ \\
\hline \multirow[t]{2}{*}{ Resources } & Still much dependent on HQ support & Less dependent on HQ support \\
\hline & & $\begin{array}{l}\text { RC Netherlands funds for HIV and CBHFA } \\
\text { IGA }\end{array}$ \\
\hline
\end{tabular}

CBHFA, Community Based Health and First Aid; HQ, Headquarter; IGA, income generation activities; PM, programme manager; RC, Red Cross; URCS, Uganda Red Cross Society.

security, belonging and intimacy with others, and the feeling of meaningful attachment to the RC.

According to the volunteers we interviewed, being involved in a well-planned intervention, benefiting from training, ongoing autonomy-supportive supervision, gaining material support and opportunities for networking, all trigger a feeling of self-efficacy. The following quotes illustrate the link between these key elements of the intervention, and the satisfaction of competence and autonomy needs:

With these skills, I am not just sitting with them at home. I make an action plan, how I am going to share the skills and the knowledge I get from RC with many people in the community. (East, male, volunteer for 4 years)

I like the knowledge I get from the first aid training. I am able to use it on myself, for example if I get a cut I can follow the required procedures of providing first aid. Most people, because they are not trained in first aid, even for a simple cut they need to go to health facilities or hospitals and meet high bills. If I am trained and I know how to handle an injury, I can use that money in other areas. (East, male, volunteer for two years)

More specifically, involving volunteers in planning, decision-making, building health and leadership skills, and allowing them to develop their own business (income-generating activities) triggers feelings of willingness, ownership and engagement in regard to activities undertaken:

When you involve someone in decision making, maybe when implementing a project, they get to know what the people want and also feel that they somehow own the project, so they will be working towards its success, even 
if they are paid or not. (East, female, youth, volunteer for four years)

A widow volunteer further explains how the RC supported her with some start-up capital for her business:

The RC supported us with some money, with a start-up capital to start different businesses. That for me... I was staying somewhere else before. This house was not like this before but because of the start-up capital I got, I was able to build a new one. Now I sell kids' clothes. I have been able to pay school fees for my son. He is at the university. Generally, life has changed. (East, female, volunteer for 12 years)

The perception of recognition and the feeling of belonging to a 'family' explain the engagement level of some volunteers. Factors such as a close relationship with the programme manager, in-kind rewards, tokens of recognition, collaboration and meetings with other volunteers, motivate the volunteers to stay engaged and to perform well through satisfaction of relatedness needs:

Recognition and respect, that is very important. As a blood donor at the end of the year, if you send me a Christmas card, for example, or a birthday card-Dear regular donor, thank you very much... You know ... Happy birthday-I will feel that I am a part of the RC. (West, male, volunteer for 20 years)

The analysis showed there is some variation regarding the key drivers of motivation. We found that the reason for joining the $\mathrm{RC}$, and also the time spent with the RC, are factors that influence how management and leadership affect volunteer motivation. In the initial stage, the $\mathrm{RC}$ volunteers are more likely to be satisfied or to remain engaged as long as the experience of volunteering fulfils their initial expectations. In general, community members feel attracted to the URCS because the $\mathrm{RC}$ activities are responsive to local needs and the organisation is recognised as a legitimate community partner. Indeed, some volunteers joined because they are intrinsically motivated and value the RC's work (strong initial match between the RC culture/value and volunteer expectations) or because they feel that the community values and recognises their contribution.

So, I joined the RC to have one heart like them, because they are very good people helping other people in our community. (West, male, volunteer for 21 years)

In a context where community health needs are high, the volunteers expect to be able to help people, and to gain the knowledge and skills enabling them to help their families and their own community. A volunteer commented:
I must say it's the satisfaction of serving the vulnerable that has pushed me and I never regretted. (East, male, volunteer for 34 years)

In the initial stage, visible and positive health results among community members are critical for the satisfaction of volunteers whose initial engagement was mainly driven by internal motives. Their intrinsic needs being covered, these volunteers enjoy the activities and experience overall satisfaction with their involvement.

Mainly, I enjoy talking to people. Sensitising, I enjoy that one most. You feel convinced, when you convince someone. When you talk to someone, then someone willingly participates and you feel that you have added value.

(West, male, volunteer for 20 years)

On the other hand, some volunteers join with a strong extrinsic motivation, meaning they are attracted by the URCS's work to obtain benefits. In a context of a competing job market, high unemployment rates and quickly changing social norms and values, such volunteers expect to gain social capital, competences and career opportunities.

I wanted to become an important person. (West, male, youth, volunteer for six years)

I came with this idea of maybe after an internship, I will get a job. So my dad was like, those big organisations are good, go there, work, be friendly and then you will get something out of it. (West, female, youth, volunteer for three months)

In the initial stage, the $\mathrm{RC}$ volunteers who join with a strong extrinsic motivation are more likely to be satisfied or to remain engaged as long as that experience of volunteering fulfils their initial extrinsic motives.

You find that more people come in with the expectations of getting jobs and payment, so whoever feels their expectations have not been met, they end up leaving. (East, female, youth, volunteer for four years)

We found that if volunteers perceive to have spent a meaningful time with the RC, a shift from external motivation towards more internalised motivation occurs. Being involved in the RC activities contributes to building an emotional link with the organisation and results in a strong belief in the $\mathrm{RC}$, and the acceptance of $\mathrm{RC}$ goals and values.

Time needs to be there so that people have a chance to be attached to the organisation, so if interesting activities are provided the volunteer will have time to come and come again, and then he will start to be attached. (West, male, volunteer for 21 years)

The satisfaction of the competence, autonomy and relatedness needs can move the motivation of extrinsically motivated volunteers towards the more internalised 
end of the scale. A young volunteer explained how her motivations shifted when she satisfied her competence need:

My first day with the URCS was so perfect. People were listening to me and I was confident [satisfaction of competence need]. After that I got the spirit of RC and I did not think about getting a job anymore. Now there is that spirit that is instilled in us even in the times of difficulties. (West, female, youth, volunteer for 3 months)

\section{CMO configurations}

In Kampala, attracting volunteers to the RC is not difficult, as the organisation is prestigious and valued, and there are many young unemployed people. Unmet health and social needs are many, and the RC provides opportunities to fulfil volunteers' objectives, such as helping people, getting a job or valuable experience, or gaining some social capital). Volunteers join because they are: (1) intrinsically motivated or driven by autonomous motivation or (2) because they are more extrinsically motivated.

In this context, the leadership and management approach deployed in the RC community health capacity-building programme (intervention) motivates community health volunteers to perform well and to stay engaged. The supportive supervision, skills and knowledge enhancement, and enabling working modalities, satisfy the three key drivers of volunteer motivation: feelings of autonomy, competence and connectedness (mechanisms). As a result, the capacity-building programme contributes to volunteers' positive work attitude, retention, task performance and well-being (outcomes).

More specifically, management practices that include proper selection, orientation, autonomy supportive supervision and skills-based training, contribute to selfefficacy and the ability to organise the work of volunteers. This is enhanced by opportunities for volunteers to meet their peers, share their experiences and solve their challenges together. Factors such as a close relationship with the programme manager, in-kind rewards and tokens of recognition, and collaboration and meetings with other volunteers, motivate the volunteers to stay engaged and to perform well.

The satisfaction of the three key drivers of volunteer motivation manifests itself differently for different volunteers. In the initial stage, $\mathrm{RC}$ volunteers are more likely to be satisfied or to remain engaged as long as that experience of volunteering fulfils their initial expectations. For the RC volunteers who join with a strong extrinsic motivation, the meaningful time that the RC volunteers spend with the RC contributes to building an emotional link with the organisation and results in a strong belief in the RC, and the acceptance of RC goals and values (increased value and mission congruence). In other words, it facilitates the shift of external motivation towards more internalised motivation. The analysis showed that if the RC organisation is accountable to their volunteers and if it respects the RC policies, transparency, and fair allocation of funds, the volunteers are more likely to generate an affective link to the organisation and to stay.

When RC volunteers are driven by more autonomous motivation, the decision to continue to be a RC volunteer is less dependent on the management/leadership and on contextual factors, such as social norms, and more influenced by the health impact of the activities within the community. In all cases, if managerial and leadership practices satisfy the competence, autonomy and connectedness needs, they have a positive impact on volunteer performance, satisfaction and well-being.

We found that, at community level, recognition was an important part of the volunteers' motivation. In Kampala, where the RC is prestigious, most of the volunteers interviewed felt attracted to the $\mathrm{RC}$ and remained volunteers because they felt they were valued by society and recognised for their contribution.

\section{DISCUSSION}

\section{The findings}

The general findings of our realist evaluation align with results from other studies on community health workers' performance and motivation, ${ }^{43-45}$ which found that a sense of relatedness to the organisation, self-efficacy, social recognition and a sense of social responsibility, motivated them to perform well. This translates into recommendations for management in terms of ensuring adequate supportive supervision, skills and knowledge enhancement and enabling working modalities.

SDT, which we used as our main framework to guide the field study, allowed us to further explain how management and leadership styles shape the motivation of individuals who start volunteering. Like other authors, ${ }^{20} 46$ we found that programme managers who support the autonomy of their staff positively influence the quality of the motivation, and that this triggers volunteers to feel self-efficacious and close to their programme manager, which in turn affects work engagement and task performance. We found that volunteers' perception of supportive supervision was an important factor of motivation, independent of the leadership style of specific managers. In the Kampala East and West branches, the leadership styles of the programme managers differed, but in both cases, the active volunteers interviewed expressed strong perceived support.

According to contingency theories, situational factors may moderate the effect of any leadership approach. ${ }^{47} 48$ We found that, in the two cases, the branch managers adapted their leadership style to the situation and to other activities of the RC volunteers. We found other factors contributing to volunteer motivation and performance, such as a good match of the organisational culture and mission with the volunteers' expectations, design of the task performed by the volunteers, and recognition from the organisation and the community. This 


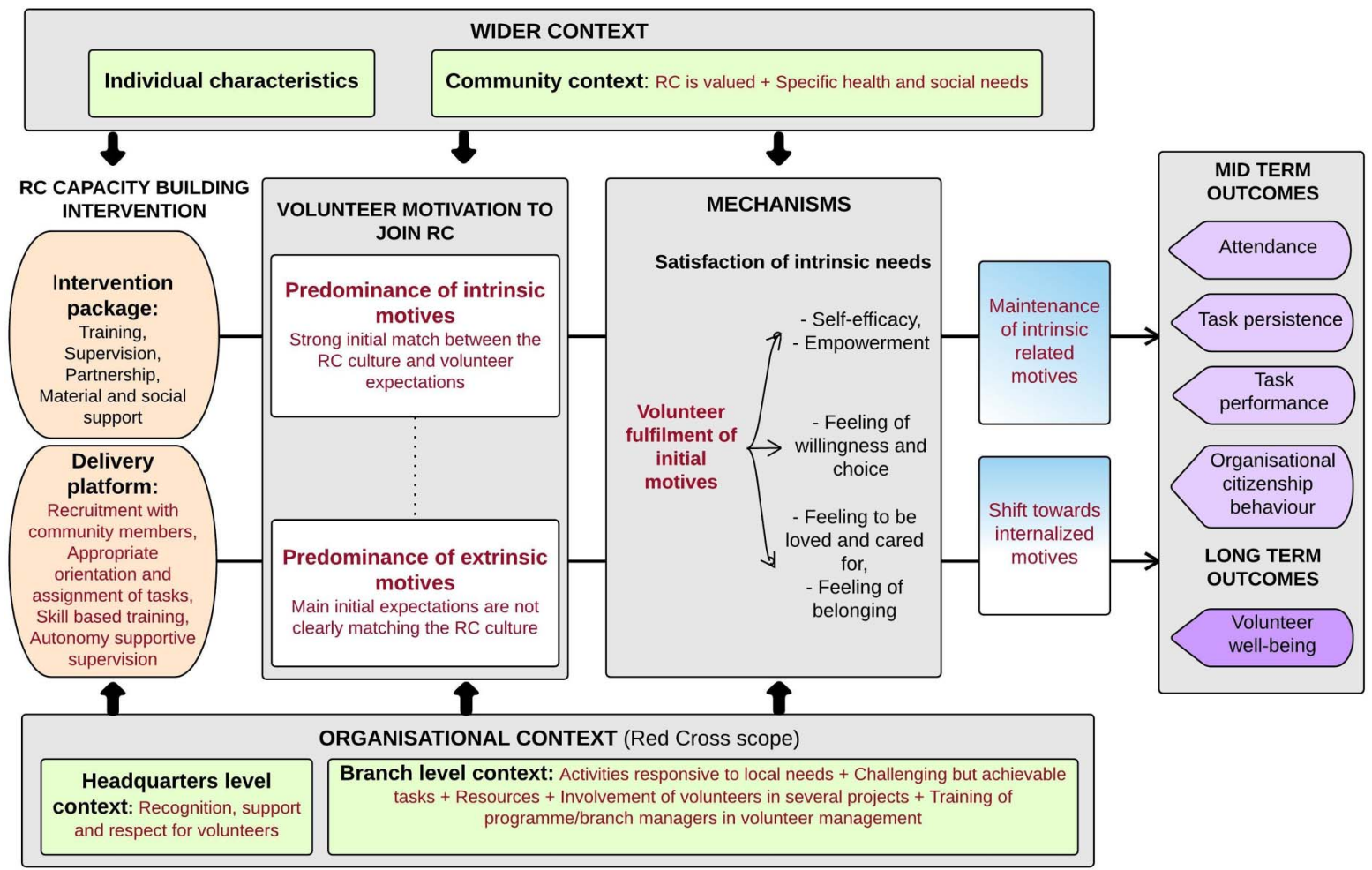

Figure 2 The refined programme theory.

has also been described previously by, for instance, Van Schie $e t a l .{ }^{46}$ We found that, at community level, recognition was an important part of the volunteers' motivation.

Management and leadership affected the key drivers of motivation for each volunteer differently, depending on the reason for joining the $\mathrm{RC}$, but also on the time spent with the RC. These results are corroborated by the findings of Chacón et $a l^{49}$ who developed the three stage model of volunteer duration. The model was created on the observation that volunteer retention and the underlying mechanisms depend on how long a volunteer has been with the organisation. While satisfaction of initial motives is a better predictor of retention in the short term, one's commitment to the organisation and how much one identifies with it was found to predict long term retention. According to the authors, managerial practices should cater to the immediate expectations of a volunteer in the short term, while ensuring the development of organisational commitment in the medium term, and the development of role identity in the long term.

This analysis allows us to modify the initial PT and to arrive at a more refined PT (figure 2):

In a community context where the organisation is responsive to local needs and recognised as a legitimate partner, an intervention to develop a pool of motivated and competent volunteers that consists of (1) recruitment with the help of community members, appropriate orientation and assignment of tasks, skill and knowledge enhancement and autonomy supportive supervision, and
(2) leadership that is responsive to individual motivation needs of volunteers, contributes to better retention, task performance and well-being of volunteers (outcomes) by satisfying the three key drivers of volunteer motivation (autonomy, competence and connectedness).

These mechanisms are triggered in specific context conditions, including organisational factors such as challenging but achievable tasks, visible results, availability of resources, involvement of the volunteers in several projects, and recognition, support and respect for volunteers by the National Society.

The main differences regarding the refined PT compared to the initial PT appear in red in figure 2.

\section{Methodological considerations}

The aim of this inquiry was to develop a refined PT that would be the starting point for the next round of realist evaluation of volunteer motivation within the Red Cross. Our refined PT offers insights on how management and leadership practices shape volunteer motivation, and in which contexts the underlying mechanisms of motivation are triggered. Such analysis helps to overcome the limitations of traditional case studies to explain the changes brought by an intervention. ${ }^{50}$ The strength of realist evaluation is indeed for its potential of developing an explanatory theory and this addresses the lack of attention to theory in implementation and knowledge translation research. ${ }^{51-53}$ Much of the research on volunteer motivation and management in general uses theory isolated from context. 
This study has some limitations. In general, limitations were imposed by the restricted time and resources, and unexpected events faced by the URCS during the study. The unforeseen restructuring process at the URCS made some of the field work very difficult. The diversity of our participants is another limitation. While efforts were made to include a wide range of volunteers, we could only interview two volunteers who left the immunisation programme after the first round of implementation. The reason given by these volunteers was the lack of time due to their involvement in other RC activities and not dissatisfaction with the programme or other such reasons. We explored the reasons for volunteer demotivation or exit in the interviews with the active volunteers, but this provided only limited insights in actual mechanisms that lead to volunteer attrition. Moreover, 'social desirability' bias may have occurred during the interviews and FGDs as well, leading to results that provided a more idealised situation than the ordinary day-to-day activities in the cases.

The two case studies allowed us to refine the initial PT, but leave some unanswered questions that deserve further exploration. For instance, we could not assess the contribution of the greater opportunity for learning and empowerment for the volunteers in Kampala East to the better retention and task performance in that branch, since we did not actually measure volunteer motivation.

Collaborative work took place between the URCS and our team to discuss key relevant 'lessons learnt' from this inquiry (practical lessons for URCS can be found in online supplementary annexe 3 ). This study contributes to the RC organisational learning at two levels: first, the resulting knowledge informs URCS on how their local operations can be improved. Making the stakeholders' assumptions explicit (development of the initial PT stage) and later providing a more detailed understanding of the mechanisms in action and the factors that matter in Kampala regarding volunteer motivation and performance, enable URCS to tailor their capacity-building intervention to their specific context. The refined PT provides a structure to build on and to be refined. Second, the iterative process of developing, testing, validating and reviewing $\mathrm{CBH}$ capacity-building interventions will allow a systematic comparison and, ultimately, contribute to the development of evidence-based insights into how $\mathrm{CBH}$ capacity-building interventions work, why they work, under which conditions they do so, and for whom. This contributes to the improvement of RCRC National Societies' programmes and to better health outcomes for underserved communities.

\section{CONCLUSION}

The aim of the study was to develop a refined PT that proposes how, why and under what circumstances RC capacity-building interventions shape the motivation of volunteers and contribute to better retention, task performance and well-being. Using realist evaluation, we identified plausible mechanisms of change (ie, drivers of motivation) that explain the link between the capacitybuilding intervention, the organisational context, and the work attitudes and work behaviour of the volunteers. We found that a management approach that caters for the different motivational states of volunteers and that is responsive to their changing needs (ie, that addresses the evolution of the psychological needs of autonomy, competence and relatedness), will lead to higher attraction, better retention rates and better task performance and well-being among the volunteers. This research informs URCS on how their local operations can be improved. Moreover, because the work presented in this article is part of a larger research project, it will also inform IFRC strategies and practices to address health issues among vulnerable communities. Indeed, RCRC National Societies are spread over 189 countries and future studies will take place in other settings. This will provide key information on how RCRC capacity-building strategies trigger mechanisms depending on the context of the programmes.

\section{Author affiliations}

${ }^{1}$ EHESP Rennes, Sorbonne Paris Cité, France

${ }^{2}$ CNRS, UMR CRAPE Centre de Recherches sur l'Action Politique en Europe,

Rennes, France

${ }^{3}$ Department of Public Health, Institute of Tropical Medicine, Antwerp, Belgium

${ }^{4}$ Department of Development, Policy and Practice, Royal Tropical Institute, Amsterdam, The Netherlands

${ }^{5}$ Department of Community Health and Innovation, International Federation of Red Cross and Red Crescent Societies, Geneva, Switzerland

Acknowledgements The authors wish to first thank the Uganda Red Cross Society and its staff for welcoming the study and facilitating it. They are especially grateful for the work and the help of Alex Onzima, Joram Musinguzi and Umaru Ntambi. Special thanks go also to volunteers Joseph Ssenkumba, Ibrahim Nkonge and Akankwasa Keneth Kategaya, for providing translations of interviews on site and overall help with the interview organisation. The authors would also like to acknowledge the inputs of the IFRC Community Health and Innovation unit, and the IFRC volunteering department, especially Ayham Alomari and Shaun Hazeldine. Finally, they thank Vivienne Seabright for English language editing of the manuscript.

Contributors All the authors contributed to conceptualising the study and to developing the tools, with leadership from GV and BM. GV and TP went to Uganda to undertake the field work. They analysed the data separately and had ongoing meetings and discussion with all the authors during this time. GV wrote the first draft of the present manuscript. All the authors reviewed and provided comments to improve the manuscript. All the authors read and approved the final manuscript.

Funding The study is funded by the International Federation of Red Cross and Red Crescent Societies (Geneva, Switzerland). Gaëlle Vareilles is the recipient of a PhD grant under the IFRC funding that provides a monthly stipend and a bench fee to cover local travel and research expenses.

\section{Competing interests None declared.}

Ethics approval Ethical approval was provided by the Ethical Committee at Rennes University Hospital, France (CHU Rennes Hotel Dieu-Rennes, France -Approval number 14.41).

Provenance and peer review Not commissioned; externally peer reviewed. Data sharing statement No additional data are available.

Open Access This is an Open Access article distributed in accordance with the Creative Commons Attribution Non Commercial (CC BY-NC 4.0) license, 
which permits others to distribute, remix, adapt, build upon this work noncommercially, and license their derivative works on different terms, provided the original work is properly cited and the use is non-commercial. See: http:// creativecommons.org/licenses/by-nc/4.0/

\section{REFERENCES}

1. Mexico City Political Declaration on Universal Health Coverage: sustaining universal health coverage, sharing experiences and promoting progress. 2 April 2012. http://www.who.int/healthsystems/ topics/financing/MexicoCityPoliticalDeclarationUniversalHealth Coverage.pdf (accessed 24 Mar 2015).

2. Lewin S, Munabi-Babigumira S, Glenton C, et al. Lay health workers in primary and community health care for maternal and child health and the management of infectious diseases. Cochrane Database Syst Rev 2010;(3):CD004015.

3. Lassi ZS, Haider BA, Bhutta ZA. Community-based intervention packages for reducing maternal morbidity and mortality and improving neonatal outcomes. Cochrane Database Syst 2010;(11) CD007754.

4. Wouters E, Van Damme W, van Rensburg D, et al. Impact of community-based support services on antiretroviral treatment programme delivery and outcomes in resource-limited countries: a synthetic review. BMC Health Serv Res 2012;12:194. http://www. ncbi.nlm.nih.gov/pubmed/22776682 (accessed 21 Aug 2014).

5. Callagan MK, Ford N, Schneider H. A systematic review of task-shifting for HIV treatment and care in Africa. Hu Resour Health 2010;8:8. http://www.human-resources-health.com/content/8/1/8 (accessed 21 Aug 2014)

6. Casiday R, Fisher C, Bambra C, et al. Volunteering and health: what impact does it really have? Report to volunteering England. Volunteering England, 2008

7. Watkins EL, Harlan C, Eng E, et al. Assessing the effectiveness of lay health advisors with migrant farm workers. Fam Community Health 1994;16:72-87.

8. Zachariah R, Ford N, Philips M, et al. Task shifting in HIV/AIDS: opportunities, challenges and proposed actions for sub-Saharan Africa. Trans $R$ Soc Trop Med Hyg 2009;103:549-58.

9. Hermann K, Van Damme W, Pariyo GW et al. Community health workers for ART in sub-Saharan Africa: learning from experiencecapitalizing on new opportunities. Hum Resour Health 2009;7:31. http://www.human-resources-health.com/content/7/1/31 (accessed 21 Aug 2014)

10. Celletti F, Wright A, Palen J, et al. Can the deployment of community health workers for the delivery of HIV services represent an effective and sustainable response to health workforce shortages? Results of a multicountry study. AIDS 2010;24(Suppl 1): S45-57.

11. Jackson SF, Perkins F, Khandor E, et al. Integrated health promotion strategies: a contribution to tackling current and future health challenges. Health Promot Int 2006;21(Supp1):75-83.

12. Bhattacharyya $\mathrm{K}$, Winch $\mathrm{P}$, LeBan $\mathrm{K}$, et al. Community health worker incentives and disincentives: how they affect motivation, retention and sustainability. Arlington, VA: BASICS/USAID, 2001.

13. Nkonki L, Cliff J, Sanders D. Lay health worker attrition: important but often ignored. Bull World Health Organ 2011;89:919-23.

14. McElroy JC, Morrow PC, Rude SN. Turnover and organizational performance: a comparative analysis of the effects of voluntary, involuntary, and reduction-in-force turn-over. J Appl Psychol 2001;86:1294-9.

15. Lehmann U, Sander D. Community health workers: what do we know about them? The state of the evidence on programmes activities, costs and impact on health outcomes of using community health workers. Geneva, Switzerland: WHO, 2007.

16. Perry HB, Zulliger R. How effective are Community Health Workers? Baltimore: Johns Hopkins Bloomberg School of Public Health; Report, 2012

17. Takasugi T, Lee AC. Why do community health workers volunteer? A qualitative study in Kenya. Public Health 2012;126:839-45.

18. Goodwin N. Leadership in health care. A European perspective. London: Routledge, 2006.

19. Gagne M. The role of autonomy support and autonomy orientation in prosocial behavior engagement. Motiv Emot 2003;27:199-223.

20. Oostlander J, Guntert ST, Van Schie S, et al. Leadership and volunteer motivation: a study using self-determination theory. Nonprofit Volunt Sect Q 2013;43:869-89.
21. Gagne M, Deci EL. Self-determination theory and work motivation. J Organiz Behav 2005;26:331-62.

22. Greenspan JA, McMahon SA, Chebet JJ, et al. Sources of community health worker motivation: a qualitative study in Morogoro Region, Tanzania. Hum Resour Health 2013;11:52.

23. Hill Z, Dumbaugh M, Benton L, et al. Supervising community health workers in low-income countries- a review of impact and implementation issue. Glob Health Action 2014;7:24085. (accessed 12 Feb 2015).

24. Wang JW, Wei C, Harada K, et al. Applying the social cognitive perspective to volunteer intention in China: the mediating roles of self-efficacy and motivation. Health Promot Int 2011;26:177-87.

25. Smith BJ, Tang KC, Nutbeam D. WHO Health Promotion Glossary: new terms. Health Promot Int 2006;21:340-5.

26. Frymus $\mathrm{D}$, Kok M, De Koning $\mathrm{K}$, et al. Knowledge gaps and a need based Global Research agenda by 2015. Working paper. Geneva, Switzerland: the Global Health Workforce Alliance, 2013. http://www. who.int/workforcealliance/knowledge/resources/CHWsResearch_ Agenda_by2015.pdf (accessed 16 Sep 2014).

27. Burton P, Goodlad R, Croft J. How would we know what works? Context and complexity in the evaluation of community involvement. Evaluation 2006;12:294-312.

28. Craig P, Dieppe P, Macintyre S, et al., Medical Research Council Guidance. Developing and evaluating complex interventions: the new Medical Research Council guidance. BMJ 2008;337:a1655.

29. Amizaki Y, Hu T, Li S, et al. Country briefing: Uganda-health. Global Health at MIT, 2011. https://globalhealth Hu,.mit.edu/ uganda-health/ (accessed 16 Sep 2014).

30. The World Bank. Uganda at a Glance. http://devdata.worldbank.org/ AAG/uga aag.pdf (accessed 16 Sep 2014).

31. United Nations, Department of Economic and Social Affairs. World population prospects: the 2012 revision. http://esa.un.org/unpd/wpp/ Excel-Data/population.htm (accessed 16 Sep 2014)

32. Uganda Red Cross Society. Mission and Vision. http://www. redcrossug.org/index.php?option $=$ com content\&view $=$ article\&id $=898$ Itemid=851 (accessed 28 Aug 2014)

33. Vareilles G, Pommier J, Kane S, et al. Understanding the motivation and performance of community health volunteers involved in the delivery of health programmes in Kampala, Uganda: a realist evaluation protocol. BMJ Open 2015;5:e006752.

34. Pawson R, Tilley N. Realistic evaluation. London: Sage Publication, 1997.

35. Marchal B, Van Belle S, De Brouwere V, et al. Studying complex interventions: reflections from the FEMHealth project on evaluating fee exemption policies in West Africa and Morocco. BMC Health Serv Res 2013;13:469.

36. Deci EL, Ryan RM. The "what" and "why" of goal pursuits: human needs and the self-determination of behavior. Psychol Inq 2000;11:227-68

37. Yin RK. Case study research: design and methods. 2nd edn. Thousand Oaks: Sage, 1994

38. Kitzinger J, Barbour RS. Introduction: the challenge and promise of focus groups. In: Barbour RS, Kitzinger J, eds. Developing focus group research; politics, theory and practice. London: Sage, 1999:1-20.

39. Deci EL, Connell JE, Ryan RM. Self-determination in a work organization. J Appl Psychol 1989;74:580-90.

40. Fram SM. The constant comparative analysis method outside of grounded theory. Qual Rep 2013;18:1-25.

41. Ragin CC. The comparative method: moving beyond qualitative and quantitative strategies. Berkeley: University of California Press, 1987

42. Pearce CL, Sims HP, Cox JF, et al. Transactors, transformers and beyond: a multi-method development of a theoretical typology of leadership. J Manag Dev 2003;22:273-307.

43. Gopalan SS, Mohanty S, Das A. Assessing community health workers' performance motivation: a mixed-methods approach on India's Accredited Social Health Activists (ASHA) programme. BM Open 2012;2:e001557.

44. Druetz T, Kadio K, Haddad S, et al. Do community health workers perceive mechanisms associated with the success of community case management of malaria? A qualitative study from Burkina Faso. Soc Sci Med 2015;124:232-40.

45. Kane S, Gerretsen B, Scherpbier R, et al. A realist synthesis of randomised control trials involving use of community health workers for delivering child health interventions in low and middle income countries. BMC Health Serv Res 2010;10:286.

46. Van Schie S, Guntert ST, Oostlander J, et al. How the organizational context impacts volunteers: a differentiated perspective on self-determined motivation. VOLUNTAS: Int $J$ Volunt Nonprofit Organ 2015;26:1570-90. 
47. Fiedler FE. A contingency model of leadership effectiveness. Adv Exp Soc Psychol 1964;1:149-90.

48. Hersey P, Blanchard P. The life cycle theory of leadership. Train Dev $J$ 1969;23:26-34

49. Chacón F, Vecina ML, Davila MC. The three stage model of volunteers' duration of service. Soc Behav Pers 2007;35:627-42.

50. Pawson R: Evidence-based policy: a realist perspective. London: Sage Publications, 2006.
51. Improved Clinical Effectiveness through Behavioural Research Group (ICEBeRG). Designing theoretically-informed implementation interventions. Implement Sci 2006;1:4.

52. Rycroft-Malone J. Theory and knowledge translation: setting some co-ordinates. Nurs Res 2007;56:S78-85.

53. Rycroft-Malone J, Bucknall T. Models and frameworks for implementing evidence-based practice. Linking evidence to action. Oxford: Wiley-Blackwell, 2010. 